\title{
Thermal Energy Storage using Phase Change Material Derived from Waste Cooking Oil: A Case Study
}

\author{
Paolo Yves L. De Silos* \\ Department of Chemical Engineering, \\ University of the Philippines Los Banos, \\ Laguna, Philippines
}

\author{
Angelli A. Ocampo \\ Department of Chemical Engineering, \\ University of the Philippines Los Banos, \\ Laguna, Philippines
}

\author{
Alyssa Mae E. Remarim \\ Department of Chemical Engineering, \\ University of the Philippines Los Banos, \\ Laguna, Philippines
}

\begin{abstract}
There is a growing necessity for energy storage due to the intermittent nature of renewable energy sources. A good alternative for energy storage is Phase Change Materials (PCM), which can store large amounts of energy at relatively small volumes at a constant temperature. In the thermal packaging industry, PCM are utilized as Thermal Energy Storage (TES) for the purpose of maintaining the temperature of a temperature-sensitive product within the desired temperature range during transportation. A possible source of PCM is lauric acid, a saturated free fatty acid which may be obtained from organic materials. Coconut oil, the most common cooking oil used in the Philippines, contains 50\% lauric acid. Hence, a plant design case study was prepared to study the viability of creating thermal energy storage using phase change material derived from waste cooking oil. As a basis for calculations and the case study, data were obtained from literature and primary sources, and the Municipality of Los Banos in the Province of Laguna was used. The designed plant can produce up to 6,200 cubic meters of PCM or 477, 000 packs per year from four manufacturing lines. Each pack may be sold at PHP 1,500 and makes approximately PHP 700 million sales annually. To initiate the plant, the basic requirements include equipment, land and building cost, raw materials, office equipment, and several operating expenses. Return-of-investments and payback period were shown to be $25 \%$ and 2 years, respectively.
\end{abstract}

Keywords: PCM, coconut oil, TES, waste-to-energy

Received: 11 May 2019; Accepted: 22 July 2019; Published: 26 August 2019

\section{INTRODUCTION}

In the field of energy conservation, the use of TES systems is vital. This kind of system enables the storage of energy for utilization at a later time. Since TES systems are known for its safe, practical, and economical technology for storing, they can be used for the daily energy needs of humans [1]. In addition, TES systems are designed to obtain energy which was accumulated, especially when production exceeds demand in order to make it available at a more desired time. It will help to regulate the supply-demand relationship of energy necessity. With this, the production of renewable sources of energy will increase, resulting in the reduction of carbon dioxide and other carbon-based fuels [2,3].

In the thermal packaging industry, PCM are utilized as thermal energy storage for the purpose of maintaining the temperature of a temperature-sensitive product within the desired temperature range during transporta-

\footnotetext{
${ }^{*}$ Correspondence concerning this article should be addressed to Paolo Yves L. De Silos, Department of Chemical Engineering, University of the Philippines Los Banos College, Laguna, Philippines. E-mail: pldesilos1@up.edu.ph

(C) 2019 The Author(s). Published by KKG Publications. This is an Open Access article distributed under a Creative Commons AttributionNonCommercial-NoDerivatives 4.0 .
} 
tion. The most common temperature range is between $80^{\circ} \mathrm{C}$ to $+40^{\circ} \mathrm{C}$; however, the $2^{\circ} \mathrm{C}$ to $8^{\circ} \mathrm{C}$ range is the most widely used [4]. The physical properties which are important in knowing the TES capacity of materials are the specific heat capacity $\left(C_{p}\right)$, melting point $\left(T_{m}\right)$, and latent heat of fusion $\left(H_{m}\right.$ or $\left.L_{f}\right)$ [1]. Phase change materials contain a relatively high heat of fusion to absorb a large amount of energy prior to melting or solidification. Its temperature remains constant even at phase change resulting in a wide variety of application. The most significant variation between the usage of PCMs and common heat-storing mediums, like water or rock, is that PCM melting point is within the range of utilization. Likewise, PCM gives advanced thermal packaging protection for products that are temperature-sensitive for storing at a specific range of temperature during transportation or shipping. The materials wherein PCMs are created are chosen intrinsically to maximize the duration of thermal control such that the temperature of phase change lies within the required temperature range of the commodity being transported. A commonly used raw material for PCM is lauric acid, a free fatty acid which makes $50 \%$ of coconut oil [5].

Coconut oil is a variety of edible oil which is obtained from kernel or meat of mature coconuts gathered from the Cocos nucifera, a coconut palm. It is known for its high saturated fat content and slow oxidation. As such, it is rancidification-resistant making it last to about 6 months at $24^{\circ} \mathrm{C}\left(75^{\circ} \mathrm{F}\right)$ without spoiling. The World Health Organization (WHO), International College of Nutrition (ICN), United States Food and Drug Administration (USFDA), American Heart Association (AHA), British National Health Service (BNHS), and Dietitians of Canada promotes the regular consumption of coconut oil in the human diet [6]. The total coconut oil production in the Philippines is about 1.52 million MT for 2012. This value is higher than the 2011 record of about 1.13 million MT. Because of shortage in the domestic supply, about $65 \%$ of the supply was exported as a result of the high prices. In addition, the consumption rate of coconut oil increase from 314,000 MT (2011) to 403,000 MT in 2012 revealing a $28 \%$ increase [7].

The global market for PCM is projected to reach US $\$ 1.5$ billion by 2020, with Europe representing the largest market worldwide followed by the Americas (North and South America). However, Asia-Pacific is predicted to rise as the fastest growing market of PCM with a projected compound annual growth rate of $16.7 \%$ primarily because of the demand for higher energy efficiency and energy-saving devices. Countries including India, Brazil, China, Russia, and South Africa are ex- pected to increase the demand for PCM over the next years. The market drivers for the demand of the product are the use of microencapsulated PCM in the textile sector, continuous technology development, efforts from the government and EPA to reduce the greenhouse gases emissions, growing demand for biodegradable materials, increasing emphasis on energy conservation, and rapid urbanization in the developing countries. In contrast to these drivers, the high cost of advanced PCM and the lack of awareness among consumers inhibits market growth. But as the suppliers innovate and improve macro and micro-encapsulation techniques, the market price will eventually go down, and it will result in more opportunities in PCM market [8]. The cost of fatty acid PCM ranges from 1.43 to 1.76 per kilogram in the United States [9].

The main objective of the study is to design a plant for the production of thermal energy storage from phase change material derived from waste cooking oil. Data used for calculations were obtained from literature and secondary data.

\section{METHODOLOGY}

The concept of the study was to conduct a feasibility study in putting up the plant, which was evaluated through market compatibility, environmental impact, energy-related application, and overall cost. Budget and schedule were calculated, and the resources needed were identified. Calculations for the whole process was done, including the material and energy balance in order to determine the specification and size of each equipment that may be needed as well as the number of machines. Working drawings for the plant site, land area allotment, and the plant layout was prepared, which includes the proper spacing of the buildings and equipment. For the selection of equipment, different suppliers were considered, and the supplier with the lowest price but high-quality machines was chosen. Since the equipment may come from different places, local or international, the time of delivery was also considered.

\section{A. Production of Thermal Energy Storage}

The thermal energy storage system manufacturing process was divided into four phases: (1) cleaning and recycling the waste cooking oil, (2) lauric acid extraction from the cooking oil, (3) phase change material production from lauric acid, and (4) packaging of the thermal energy storage system.

Refined-Bleached-Deodorized (RBD) cooking oil is the most widely used form of coconut because of its importance as a raw material to various process yielding 
substantive products. Since the raw material to be used in the TES production are used coconut oil (UCOIL), primary treatment is necessary to removed unwanted par- ticles in the UCOIL, together with the effects of cooking in it (Fig. 1) [10, 11, 12, 13, 14].
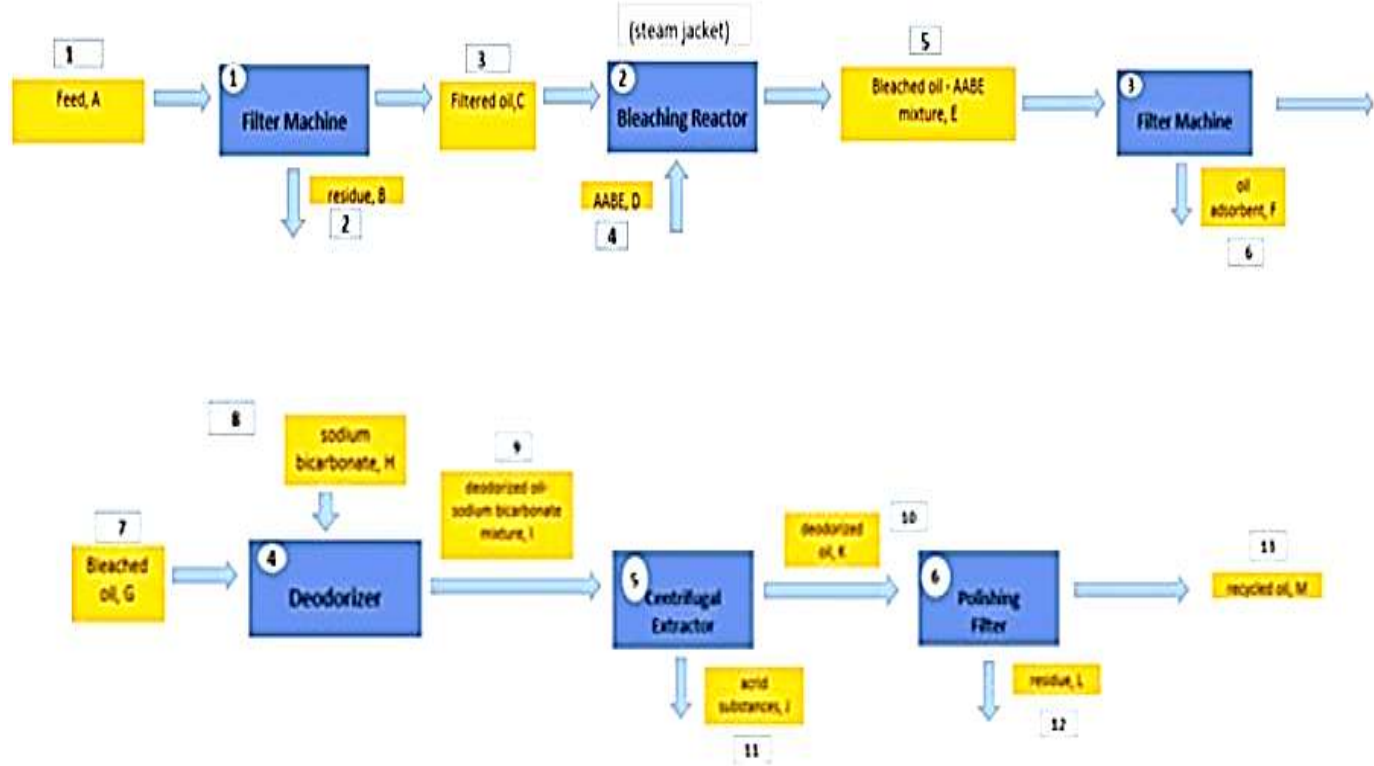

Fig. 1. Waste cooking oil cleaning and recycling

For the lauric acid extraction from the recycled cooking oil, four steps were needed: neutralization, transesterification, extraction, and hydrolysis (Fig. 2, 3, 4, 5). The n-hexane and $\mathrm{Na}_{2} \mathrm{CO}_{3}$ are needed to neutralize the coconut oil. The water-soluble and excess moisture is to be removed using centrifugal mixer and dehydrator. Then, methanol and $\mathrm{K}_{2} \mathrm{CO}_{3}$, are added to the mixture, producing glycerol as a by-product. After which, n-hexane and $\mathrm{Na}_{2} \mathrm{CO}_{3}$ are added again producing dry methyl ester via a dehydrator. Afterwards, the dry methyl ester is to be passed through a distillation column to separate the methyl laurate component and to leave the other methyl ester components in the bottoms. The condenser shall be used to obtain the liquid methyl laurate. Finally, the liquid methyl laurate will be mixed with sodium hydroxide and distilled water in a CSTR to produce hydrolyzed methyl laurate which will be added with n-hexane and $\mathrm{HCl}$ to acidify and will be placed in a centrifugal extractor to produce the lauric acid $[15,16,17,18,19]$.

The lauric acid extracted is to be mixed with stearic acid, having a 76:24 per cent by weight ratio and mixed in a blending tank (Fig. 6). Afterwards, the mixture is to be combined with expanded carbon with a 90:10 per cent by weight ratio. The expanded carbon affects the rate of the energy transfer between the PCM and the commodity being taken care of $[20,21,22]$. 

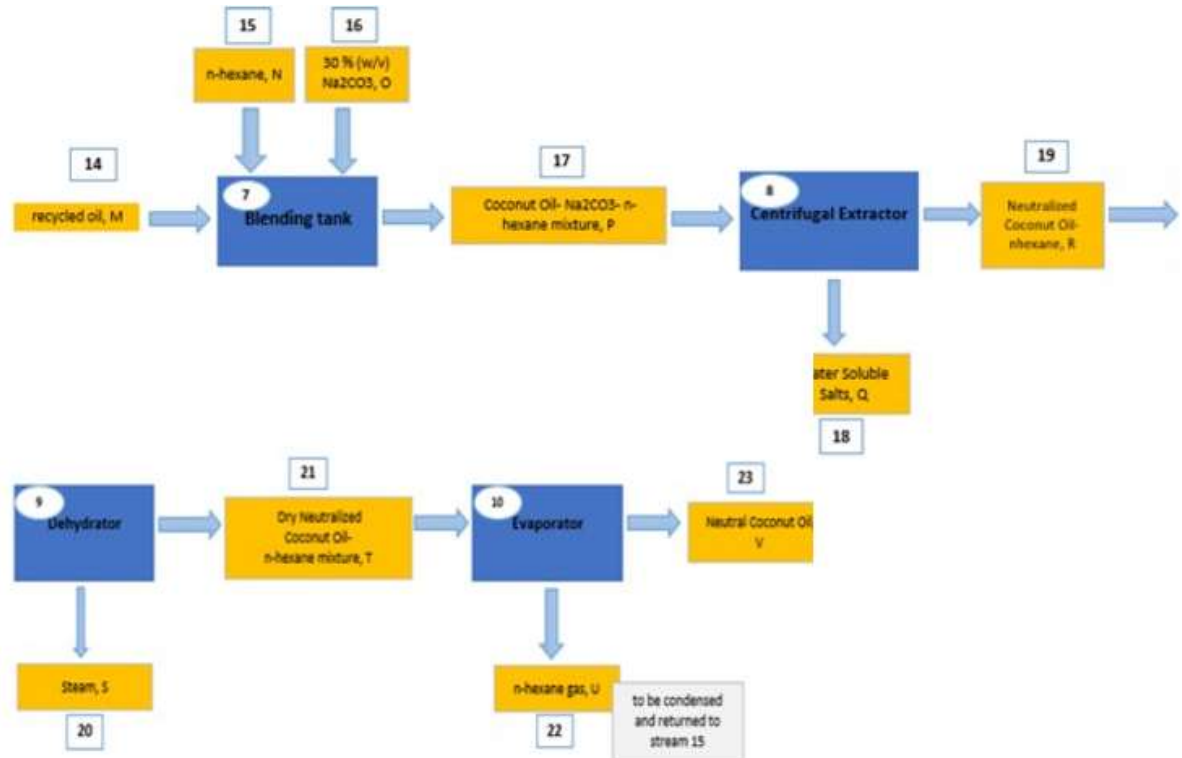

Fig. 2. Lauric acid extraction from cooking oil - neutralization
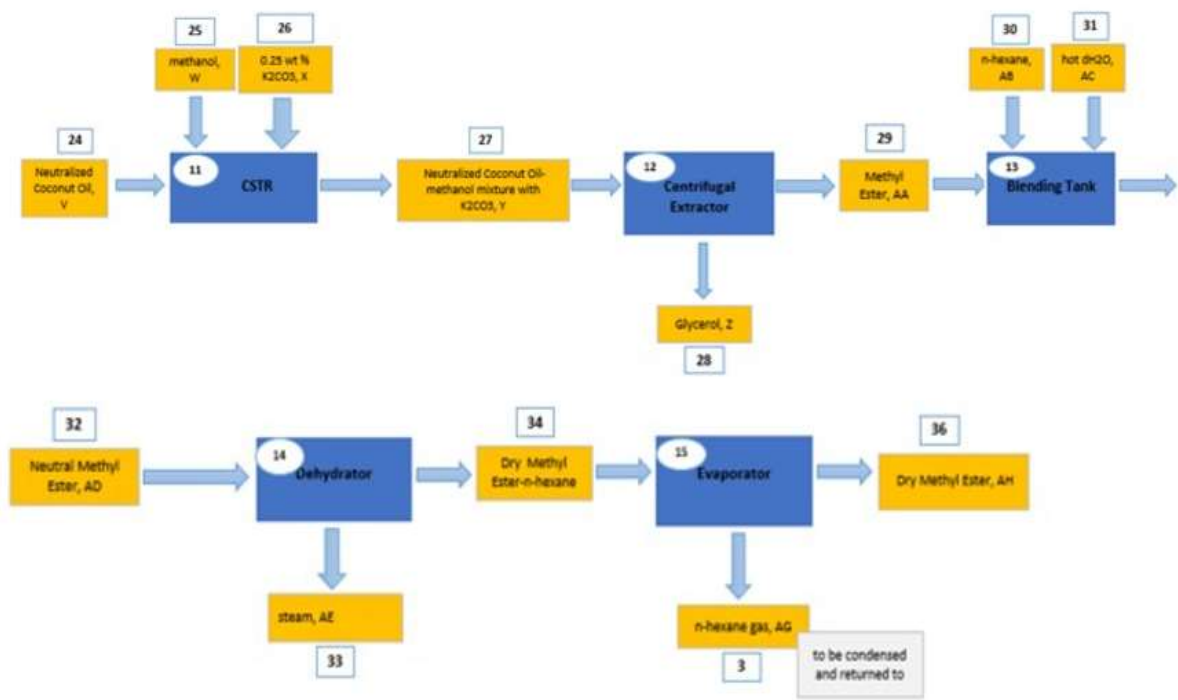

Fig. 3. Lauric acid extraction from cooking oil - transesterification

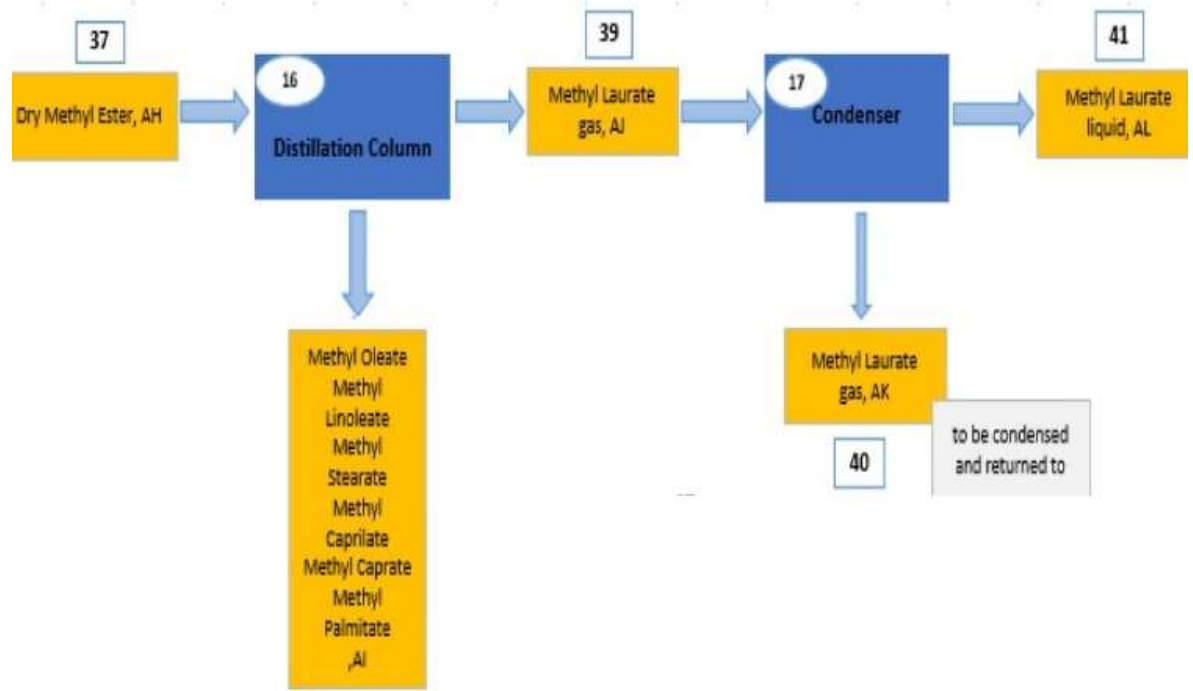

38

Fig. 4. Lauric acid extraction from cooking oil - extraction 

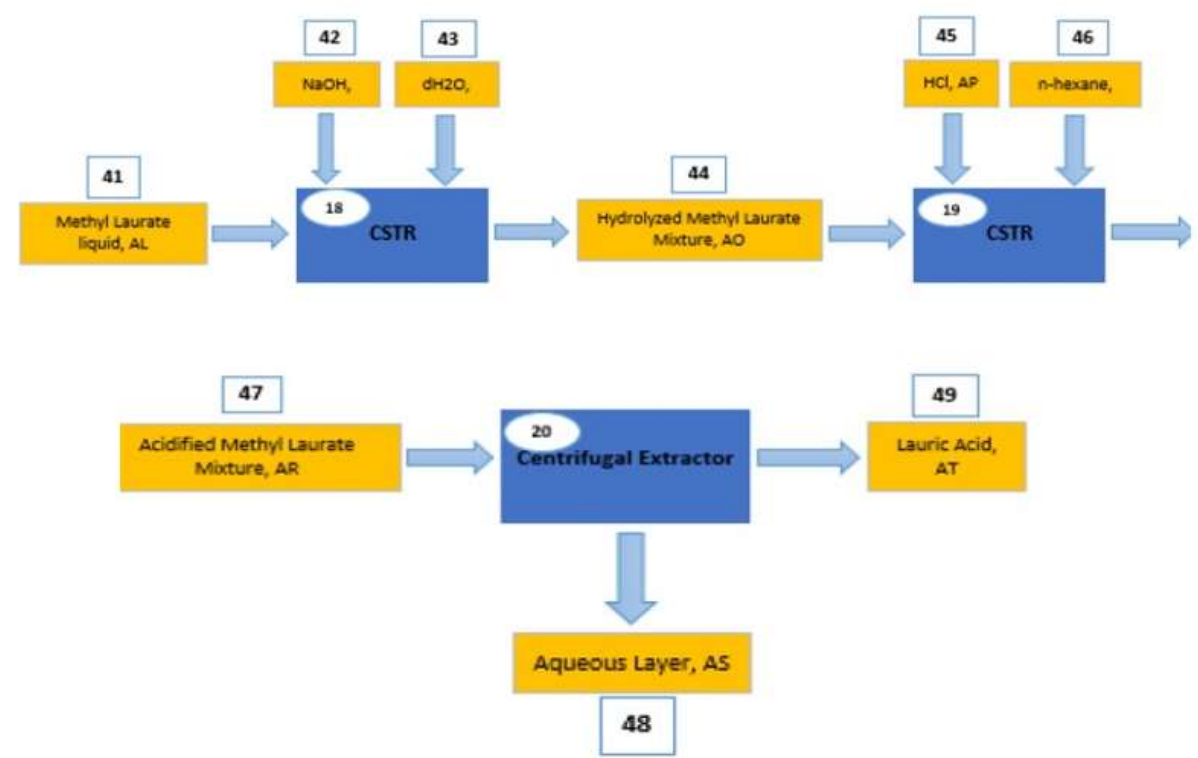

Fig. 5. Lauric acid extraction from cooking oil - hydrolysis

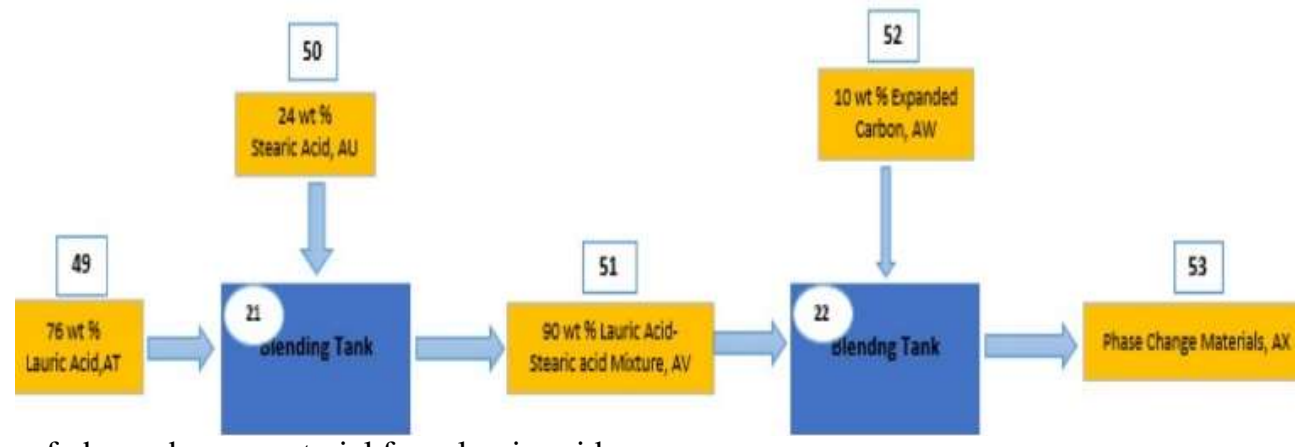

Fig. 6. Production of phase change material from lauric acid

The produced PCMs will be filled in the thermal packaging material in order to easily cool, handle, store, and transport the product. From 25 degrees Celsius, the tem- perature is lowered to 0 via cooling and stored at $1 \mathrm{~atm}$ (Fig. 7) [23, 24, 25].

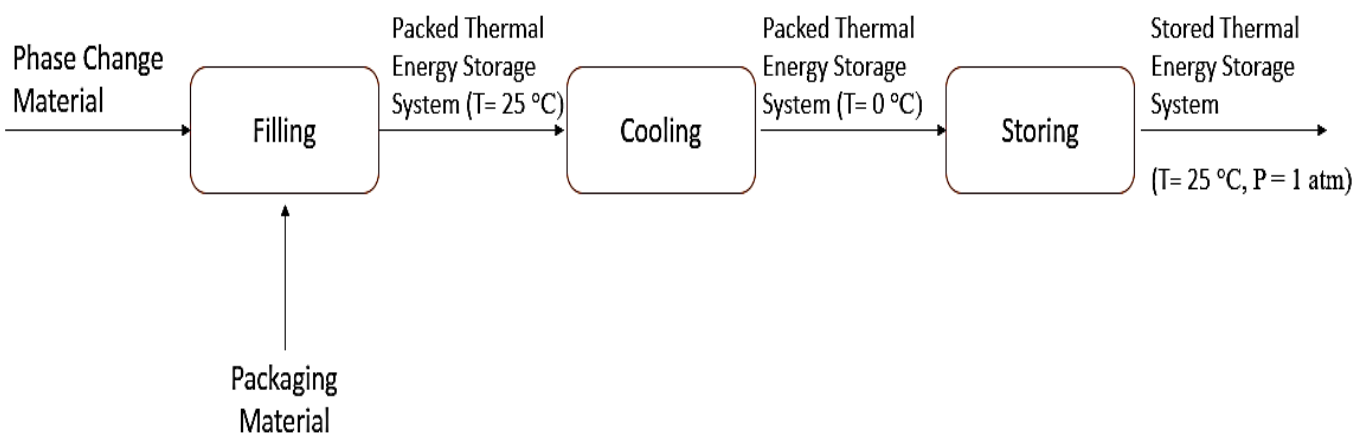

Fig. 7. Packaging of thermal energy storage from PCM

\section{B. Plant Location, Layout, and Structures}

The plant shall be located within the 69.99 hectares of Special Economic Zone (SEZ) to be established by the Philippine Economic Zone Authority (PEZA), accrediting UP Los Banos proposal for economic development in the highly science and nature-themed municipality. The SEZ will be divided into a 9.15 ha information technology hub and a 60.84 ha agro-industrial park, which would then form the UPLB Agro-Industrial Information and Technology Parks to rise at the Brgy, Putho-Tuntungin, Los 
Banos, Laguna. Moreover, the municipal government of Los Banos through a May 2011 resolution supported and endorsed the application to betterment the business, technological-advancement and utilization, and job opportunities.

Likewise, being under a PEZA Special Economic Zone has some advantages, such as fiscal and non-fiscal incentives. Some of the fiscal incentives are Income Tax Holiday (ITH) or 100\% exemption from corporate income tax; 5\% Special Tax on Gross Income upon expiration of ITH; tax and duty-free importation of raw materials, capital equipment, pieces of machinery, and spare parts; exemption from wharfage dues and export tax, VAT zerorating of local purchases, and exemption from payment of any and all local government imposts, fees, licenses, or taxes. On the other hand, for the non-fiscal incentives, the following are given: Simplified Import-Export Procedures, employment of non-resident foreign nationals, and granting of Special Non-immigrant Visa with Multiple Entry Privileges [26].

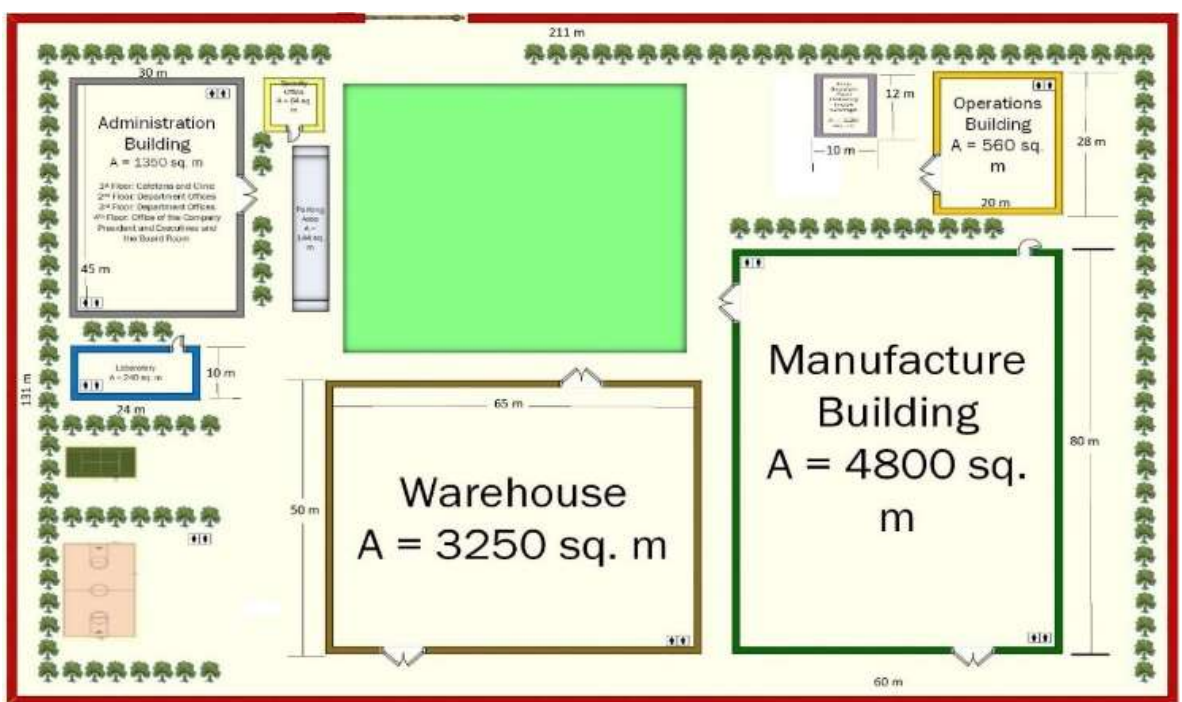

Fig. 8. Layout of the thermal energy storage plant. Total land area of the plot $=27,600 \mathrm{~m}^{2}$

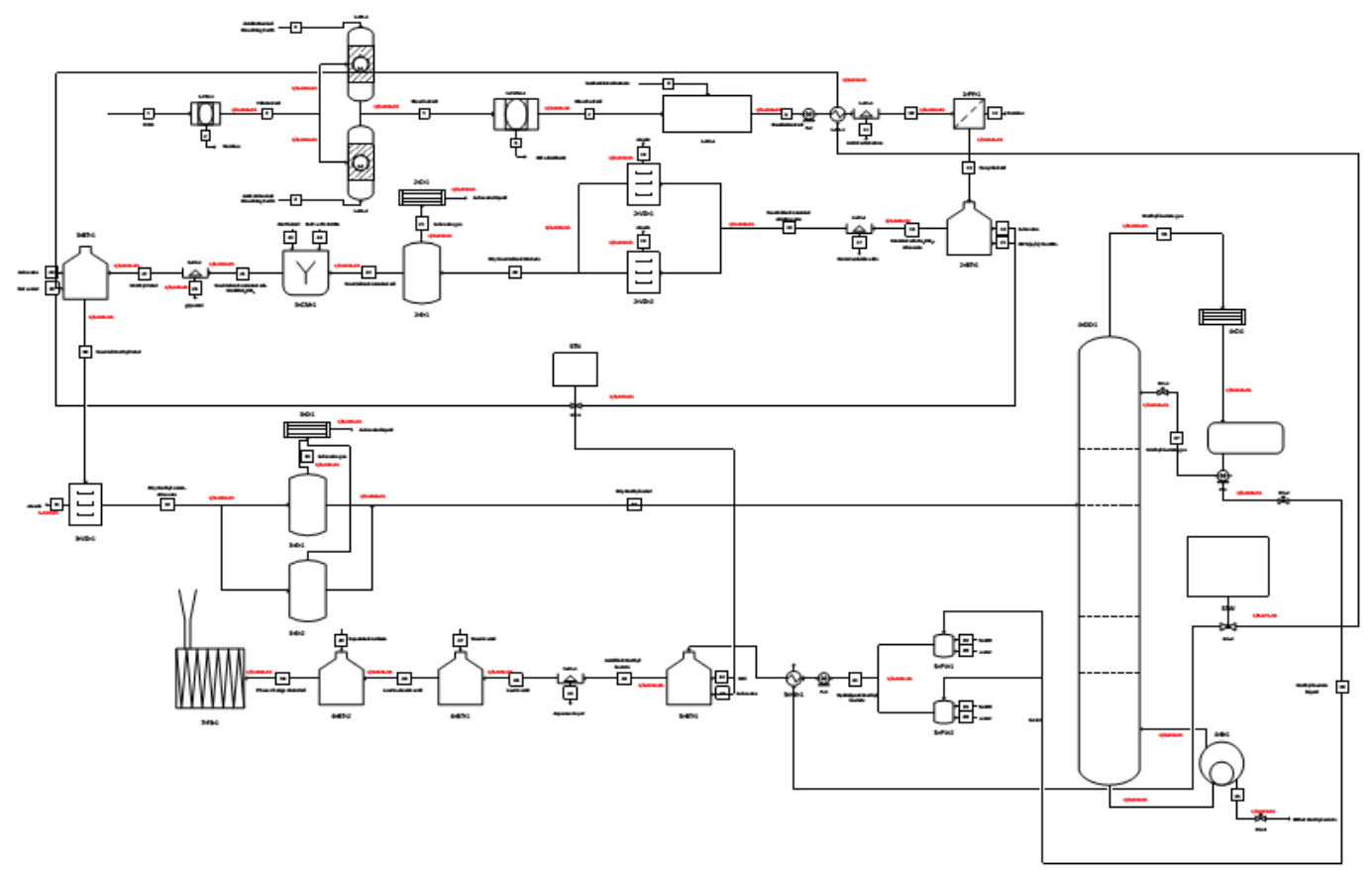

Fig. 9. Layout of the equipment layout for a single line

The structures within the plant are the manufacturing area, operation building, warehouse, clinic, canteen, laboratory, fire station and delivery truck garage, admin- istration building, security office, and the parking area (Fig. 8). The fire station is necessary for preventing and exhausting accidents involving fire. It would lessen the 
impact of such accidents in the plant. The garage for the delivery truck was placed in the same area as that of the fire station for space-saving. The parking space with an area of $144 \mathrm{~m}^{2}$ is also needed for the cars of the employees, executives, and visitors. Designated parking space and ramp for persons-with-disability have been placed in consideration with people with special needs.

The warehouse is located near the manufacturing area for ease in raw material and product transport. It has a floor area of $3,250 \mathrm{~m}^{2}$. In addition, the administration building has a floor area of $1,350 \mathrm{~m}^{2}$. With a minimum of $10 \mathrm{~m} 2$ area per person, a maximum of 135 persons can be accommodated per floor. The administration building shall have four floors. The first floor will be composed of the reception area, together with the clinic and the plant cafeteria. The second and third floors shall be composed of the offices of the various departments consisting of the company. Moreover, the fourth floor will be reserved for the offices of the executives and the company president. The board room or meeting room shall also be placed on this floor. Furthermore, a laboratory is situated near the administration building for immediate and efficient communication. It has a floor area of $240 \mathrm{~m}^{2}$.

The manufacturing area shall consist of two floors. Each floor will have two lines of production. This is to ensure that the production will not be hindered by the problems of a single line, such as equipment shutdown or breakage. Moreover, the operations building shall have an area of $560 \mathrm{~m} 2$. The control and management of the plant and warehouse shall occur in this facility. The controls and maintenance area shall be located here. The structures and proposed floor area are listed in Table 1.

TABLE 1

SUMMARY OF PLANT STRUCTURES

\begin{tabular}{ll} 
Structure & Floor Area, $m^{2}$ \\
\hline & \\
Operations Building & 560 \\
Manufacturing Area & 4,800 \\
Warehouse & 3,250 \\
Security Office & 64 \\
Administration Building & 1,350 \\
Laboratory & 240 \\
Fire Station and Delivery & 120 \\
Truck Garage & \\
Parking Area & 144 \\
\hline
\end{tabular}

The layout of the equipment in a single line (Fig. 9) consists of filtration, bleaching, deodorization, heat exchange, extraction, mixing, condensation, evaporation, distillation, packaging, and storage equipment. A summary is listed in Table 1.

TABLE 2

SUMMARY OF EQUIPMENT

\begin{tabular}{lll}
\hline \multirow{2}{*}{ Process } & Equipment & Quantity \\
\hline \multirow{3}{*}{ Filtration } & Oil Filtration Machine & \\
& Micron-Pro Continuous Oil Filters & 1 \\
Bleaching & Polishing Filter & 1 \\
& Bleaching Reactor & 1 \\
Deodorization & Deodorizer & 2 \\
Heating/Cooling & Vacuum Oil Dehydrator & 1 \\
Extraction & Heat Exchanger & 1 \\
& Centrifugal Extractor/Spinner Machine & 2 \\
Mixing & Blending Tank & 4 \\
& Centrifugal Mixer & 5 \\
Condensation & Pressure Vessel & 1 \\
Evaporation & Condenser & 1 \\
Distillation & Evaporator & 3 \\
Heating & Distillation Column (Tray) & 3 \\
Packing & Boiler & 1 \\
& Filling and Sealing & 1 \\
Storage & Water Storage Tank (Vertical on Concrete) & 1 \\
\hline
\end{tabular}


Operating expenses are listed in Table 3. These innection costs. A total of PHP 71,713,360 was calculated. clude transportation, electricity, water, and internet con-

TABLE 3

OPERATING EXPENSES

\begin{tabular}{llll}
\hline Utility & Unit Cost (PHP/Unit) & Daily Usage & Total Cost (PHP) \\
\hline & & & \\
Fuel (L) & 39.88 & 200 & $2,392,800$ \\
Delivery Trucks & 39.88 & 200 & $2,392,800$ \\
Tank Trucks & 39.88 & 200 & $2,392,800$ \\
Fire Trucks & 39.88 & 60 & 717,840 \\
Company Vehicles & 39.88 & 100 & $1,196,400$ \\
Service Vans & 10.42 & 20,000 & $62,520,000$ \\
Electricity (kW) & 0.012 & 200 & 720 \\
Water (L) & & & 100,000 \\
Internet Connectivity & & & 71713360 \\
TOTAL (PHP) & & & \\
\hline
\end{tabular}

\section{Plant Size and Production Schedule}

The proposed plant has a total land area 30, 000 $\mathrm{m}^{2}$. The space for possible expansion of the plant facilities is already incorporated to give ease in renovation and upgrading. In addition, vacant and unutilized lots are still available in the vicinity of the plant in case the initial land area is not sufficient. Assuming 300 working days in a year and 8 working hours in a day, the expected production of phase change material is $5,172,152 \mathrm{~L}$ per year. However, the production capacity may vary depending on the weather and the presence of unexpected circumstances, such as power outage and labor-related reasons.

\section{Waste Disposal and Management}

In every facility, the presence of proper and wellregulated waste disposal system is vital. The waste such as filter cakes will be sold to the agricultural sector as possible fertilizer because of the presence of NPK. Moreover, the glycerol can be sold because it is a raw material for soap making, and the methyl ester can be processed for biodiesel. Other wastes will be allowed to stay and settle in the tanks for at most two weeks. This will then be sent to wastewater treatment facilities to minimized environmental impacts.

\section{DISCUSSION}

The Philippine industrial financing can be categorized into four: financial needs for the expansion of existing companies, financing needs for the establishment of new industries or business enterprises, additional financial requirements brought about by increasing price levels, and financing needs due to general credit tightness in the economy and the corresponding need for business organizations to assume a greater financing burden on behalf of their customers [26].

The PCM production plant is a new industry in the country. The general sources of funds that companies utilize to begin their project come from personal capitalization or their own money, corporate bank loans from local or foreign banks and foreign or local investors. The government also provides fund sources specifically through the Land Bank of the Philippines (LBP) and Development Bank of the Philippines (DBP). The Department of Trade and Industrys Bureau of Investments (BOI) is another government institution that could assist in funding. The Department of Energy (DOE) gives the endorsement to BOI to prioritize the company. The BOI provides tax incentives for around 5 years referred to as Income Tax Holiday (ITH) to new businesses in Renewable Energy. This is an exemption from paying income taxes that is typically $30 \%$. Furthermore, depending on the lender or owners of the company, private banks in the country such as Union Bank, Banco de Oro (BDO) and Bank of the Philippine Islands (BPI) are also a major finance help. On the other hand, the investors can provide major assistance in the financial needs of the start-up. They can give a great influx of capital with a usual minimum amount of PHP 100M. However, the projects reliability must be ensured prior to investment. They will also act as a Joint Venture (JV) or in some case, Build Operate Transfer (BOT) of 
the company.

The production plant for PCMs is a pioneer in the country. Generally, the government, as the regulating institution, will attain financial benefits from the company through taxes. Major sources will include the taxes from the revenue of imports and exports of the plant. Also, the tax collected from the income of employees and the corporation will contribute to the revenue of the government. As the company is the first to manufacture PCMs in the Philippines, the first six years of plant operation will be exempted from paying taxes.

The raw materials involved in the manufacture are waste cooking oil from fast-food chains that typically proceeds to biodiesel production plants. Similarly, the production of phase change materials contributes to the waste-to-energy conversion of waste cooking oil.

\section{CONCLUSION}

The main product is a thermal energy storage which is an alternative and relatively inexpensive storage for pharmaceutical products. One of the most important considerations in the pharmaceutical industry is storage. This is necessary especially to highly temperaturesensitive materials, such as vaccines or biological living agents. The advantages of PCMs can also be extended to the construction industry. They can also be applied as air cooling or heating units. This generally reduces the energy consumption from the use of conventional air conditioning machines and heaters.

Mainly, the PCMs produced will cater to consumers within the pharmaceutical and construction industries. The companies producing pharmaceutical products can utilize PCMs as storage of final products as well as storage during transport. Aside from large organizations, the PCMs could also be used by pharmacies selling medicines. Hospitals, clinics and medical practitioners could utilize this for handling related materials. Moreover, in the construction of buildings and residential homes, PCMs could be used as an alternative for centralized heating and cooling.

As a corporation, the plant is capable of providing many job opportunities. Approximately, 500-1000 jobs for both skilled and non-skilled workers can be offered that will be a great help for many Filipinos. The local citizens around and within the area of Laguna will largely benefit from this. The specific areas for employment will include the management, production area, monitoring equipment and maintenance.

The production plant will provide numerous benefits to society. Initially, jobs can already be provided for the construction of the plant infrastructure. The local citizens could largely benefit from the workforce that the company will need with their opening. Professionals and even non-professionals will be able to utilize these job opportunities and generally contribute to a decrease in the unemployment rate.

The use of PCMs as thermal energy storage for pharmaceutical products is also very beneficial for the environment as it requires less energy usage relative to typical freezing or cooling equipment. Similarly, PCMs can be used as alternative air conditioning and heating units.

The designed plant can produce up to 6,200 cubic meters of PCM or 477, 000 packs per year from four manufacturing lines. Each pack may be sold at PHP 1,500 and makes approximately PHP 700 million sales annually. To initiate the plant, the basic requirements include equipment, land and building cost, raw materials, office equipment, and several operating expenses. Return-ofinvestments and payback period were shown to be $25 \%$ and 2 years, respectively, making the plant financially desirable.

\section{ACKNOWLEDGMENT}

Gratitude is given to Engr. John Kervin Sunga and Engr. Gino Guerrero in guiding us in preparing and zanalyzing this case study. Appreciation is also given to $\mathrm{Mr}$. Carl Cepeda and Ms. Cyrielle Lorio for the support in the conduct of the case study.

\section{REFERENCES}

[1] G. P. Berera. (2016) Thermal energy storage systems stearic/lauric acid mixtures as phase change materials. [Online]. Available: https://bit.ly/2zhrTyT

[2] IRENA. (2016) Thermal energy storage: Technology brief. [Online]. Available: https: //bit.ly/2We6vUn

[3] S. Sarkar and V. Ilango, "Improvement of fuel cell performance by application of carbon nanotubes," International Journal of Technology and Engineering Studies, vol. 2, no. 6, pp. 180-184, 2016. doi: https://doi.org/10.20469/ijtes.2.40003-6

[4] Cryopak. (2016) Phase change materials. [Online]. Available: https://bit.ly/2YKorYu

[5] T. Hasenohrl. (2009) An introduction to phase change materials as heat storage mediums. [Online]. Available: https://bit.ly/3fudyQf

[6] S. W. Adkins, M. Foale, and Y. Samosir, Eds., Coconut revival - new possibilities for the tree of life, Cairns, Australia, 2005.

[7] Malaysian Palm Oil Council. (2012) Oils \& fats 
scenario in the Philippines. [Online]. Available: https://bit.ly/35HBRWE

[8] Global Industry Analysts, "Advanced phase change materials (pcm): A global strategic business report," Tech. Rep., 2015. [Online]. Available: https://bit.ly/3drjJ5I

[9] J. Kosny, N. Shukla, and A. Fallahi, "Cost analysis of simple phase change material-enhanced building envelopes in southern US climates," US Department of Energy, Cambridge, MA, Report no. DOE/GO-102013-36926076, 2013.

[10] E. S. Mettawee and A. Ead, "Energy saving in building with latent heat storage," International Journal of Thermal \& Environmental Engineering, vol. 5, no. 1, pp. 21-30, 2013.

[11] A. Kacharia. (2012) Bleaching and bleaching processes. [Online]. Available: https://bit.ly/3fwOR5S

[12] S. M. Silva, K. A. Sampaio, R. Ceriani, R. Verhé, C. Stevens, W. D. Greyt, and A. J. Meirelles, "Adsorption of carotenes and phosphorus from palm oil onto acid activated bleaching earth: Equilibrium, kinetics and thermodynamics," Journal of Food Engineering, vol. 118, no. 4, pp. 341-349, 2013. doi: https://doi.org/10.1016/j.jfoodeng.2013.04.026

[13] R. Berbesi, D. Brooks, and A. S. Hodgson. Optimization of bleaching process. [Online]. Available: https://bit.ly/2YLEqoP

[14] W. Greyt. (2014) Deodorization. [Online]. Available: https://bit.ly/2WfiHEn

[15] Ecology and Combustion. (2016) Deodorizing equipment. [Online]. Available: https: //bit.ly/2YLbsWq

[16] Y. Wong and H. Hartina, "Virgin coconut oil production by centrifugation method," Oriental Journal of Chemistry, vol. 30, no. 1, pp. 237-245, 2014. doi: https://doi.org/10.13005/ojc/300129

[17] N. T. Nguyen, "Optimization of biodiesel production plants chemical and biomolecular engineering," University of Nebraska, Lincoln, USA, Unpublished doctoral dissertation, 2012.
[18] F. O. Nitbani, Jumina, D. Siswanta, and E. N. Solikhah, "Isolation and antibacterial activity test of lauric acid from crude coconut oil (cocos nucifera 1.)," Procedia Chemistry, vol. 18, pp. 132-140, 2016. doi: https://doi.org/10.1016/j.proche.2016.01.021

[19] European Biofuels Technology Platform. (2011) Fatty acid methyl esters. [Online]. Available: https://bit.ly/3bcaxRq

[20] P. C. Narvaez, S. M. Rincon, L. Z. Castaneda, and F. J. Sanchez, "Determination of some physical and transport properties of palm oil and of its methyl esters," Latin American Applied Research, vol. 38, no. 1, pp. 1-10, 2008.

[21] M. J. Pratas, S. Freitas, M. B. Oliveira, S. C. Monteiro, A. S. Lima, and J. A. Coutinho, "Densities and viscosities of fatty acid methyl and ethyl esters," Journal of Chemical \& Engineering Data, vol. 55, no. 9, pp. 3983-3990, 2010.

[22] R. A. Perkins and M. L. Huber, "Measurement and correlation of the thermal conductivities of biodiesel constituent fluids: Methyl oleate and methyl linoleate," Energy \& Fuels, vol. 25, no. 5, pp. 2383-2388, 2011. doi: https://doi.org/10.1021/ ef200417x

[23] M. H. Joshipura and R. J. Patel, "Modeling vapor pressure of fatty acid and fatty acid methyl esters using cubic equations of state," Asia-Pacific Journal of Chemical Engineering, vol. 10, no. 2, pp. 170-177, 2014. doi: https://doi.org/10.1002/apj.1859

[24] D. R. Lide, CRC handbook of Chemistry and Physics. Boca Raton, FL: CRC Press, 2005.

[25] L. Holmes and S. Krupnick. (2012) Advanced phase change materials (PCMs): Maintain product integrity while increasing performance, operational efficiency and sustainability. [Online]. Available: https://bit.ly/2La7SN1

[26] Philippine Economic Zone Authority. (2016) Fiscal incentives to PEZA-registered economic zone enterprises. [Online]. Available: https://bit.ly/2LbPfJa 